\title{
NASKAH LONGSER KARYA H. R HIDAYAT SURYALAGA SEBAGAI BAHAN PANGAJARAN DI SMA/MA/SMK (Ulikan Struktural-Sémiotik)
}

\author{
Arif Firmansyah \\ SMK Negeri 2 Cilaku Cianjur \\ email: arsyah_ners@yahoo.co.id
}

\begin{abstract}
Abstrak
Dewasa ini peminat drama longser semakin menurun, hal itu disebabkan oleh sajian cerita yang ditampilkan tidak sesuai dengan keadaan di masa sekarang. Tujuan diadakan penelitian ini adalah untuk mengidentifikasi dan mendeskripsikan karya sastra, khususnya naskah longser kemudian diterapkan sebagai bahan pembelajaran di SMA/MA/SMK. Penulis menggunakan dua metode penelitian, yaitu metode deskriptif analitis dan struktural-semiotik. Sumber data yang digunakan dalam penelitian ini adalah dari kumpulan naskah drama karya H.R Hidayat Suryalaga yang tidak diterbitkan, difokuskan pada dua naskah longser yang berjudul "Mad Toing" dan "Tisolédat". Setelah proses identifikasi terhadap naskah longser tersebut dapat dideskripsikan kedua naskah tersebut bertemakan tentang kemanusiaan yaitu mengenai masalah moral dan masalah sosial yang sedang berlangsung.
\end{abstract}

Kata Kunci: naskah longser, bahan pangajaran, struktural-semiotik

\section{LONGSER MANUSCRIPT BY H. R HIDAYAT SURYALAGA AS TEACHING MATERIAL AT SMA/MA/SMK (SENIOR HIGH SCHOOL/ RELIGIOUS HIGH SCHOOL/ VOCATIONAL HIGH SCHOOL): A STRUCTURAL-SEMIOTIC ANALYSIS}

\begin{abstract}
Nowadays interest in the longser drama is increasingly declining, which is due to the fact that its presentation does not fit with the current situation. The goal of this study was to identify and describe literature works, in particular the manuscript oflongser as a teaching material at SMA/MA/ $S M K$. Two research methods were used, namely a descriptive analytical method and a structuralsemiotic method. The data stemmed from the unpublished collection of drama manuscripts by H.R Hidayat Suryalaga, focusing on two longser manuscripts entitled "Mad Toing" and "Tisolédat". Examination of the manuscripts indicates that the main theme of the texts is humanity, specifically the moral and social issue in modern day times.
\end{abstract}

Keywords: longser manuscript, teaching material, structural-semiotic

\section{PENDAHULUAN}

Salah satu cara untuk membangun karakter bangsa yaitu melalui dunia pendidikan, dan dapat dikhususkan dalam pembelajaran sastra. Karya sastra digunakan sebagai media untuk membangun kesadaran siswa dalam menjalani hidupnya. Dalam karya sastra itu sendiri terdapat nilai sosial budaya, nilai kemanusiaan, nilai pendidikan.

Sastra Sunda dibagi menjadi dua yaitu, sastra Sunda klasik dan sastra Sunda modern (Koswara, 2011: 2). Berdasarkan bentuknya 
karya sastra dibagi menjadi tiga, yaitu puisi, prosa, dan drama. Yang difokuskan dalam penelitian ini yaitu tentang drama. Drama adalah cerita fiksi dalam bentuk tulisan atau kata-kata yang mempunyai unsur instrinsik dan ekstrinsik.

Tujuan utama dalam pembelajaran drama adalah memerankan satu tokoh dalam sebuah pertunjukan. Proses pemeranan ini tidaklah gampang, oleh sebab itu guru mempunyai tanggung jawab untuk memperkenalkan tentang pembelajaran drama. Dalam kenyataannya kebanyakan guru tidak mampu memberikan materi mengenai drama yang benar. Hal tersebut disebabkan oleh kemampuan guru yang tidak menguasai materi. Guru tidak bisa memberi contoh bagaimana pemeranan yang baik, atau guru tidak menggunakan metode yang menarik dalam pembelajarannya.

Beberapa naskah drama ditulis untuk dipentaskan. Dewasa ini siswa lebih menyukai melihat suatu pertunjukan daripada membaca naskahnya, faktor tersebut disebabkan karena sulitnya menemukan naskah drama yang diterbitkan. Akibatnya telaah atau kritik drama jadi barang yang langka.

Salah satu genre drama Sunda, yaitu longser. Longser berfungsi sebagai sarana hiburan masyarakat pada masanya, tapi sekarang longser sudah tidak dikenal lagi. Isi dari cerita longser sudah tidak sesuai dengan kebutuhan di masa sekarang. Jika dibandingkan dengan penulis cerpen, puisi, atau novel, tidak banyak pengarang yang menulis naskah drama Sunda, terutama naskah longser. Lahan untuk menerbitkan naskahnya pun tidak ada. Hal tersebut terlihat dari sulitnya mencari buku kumpulan naskah longser.

Ada beberapa hal yang harus diperhatikan dalam memilih bahan pembelajaran. Sebuah materi pembelajaran harus sesuai dengan kemampuan siswa. Bahan pembelajarannya drama khususnya longser harus memberikan kontribusi dalam menumbuhkan nilai budaya lokal.

\section{Metode}

Metode yang digunakan dalam penelitian ini adalah metode deskripstif analisis yang dipakai untuk mengolah data yang sudah ada. Prosedur yang dilakukan dalam metode deskriptif meliputi (a) analisis, (b) interpretasi, dan (c) evaluasi. Metode khusus yang digunakan dalam penelitian ini adalah metode strukturalsemiotik. Metode struktural digunakan untuk mendeskripsikan struktur drama yang ada dalam naskah longser "Mad Toing" dan “Tisolédat". Metode semiotik digunakan untuk menidentifikasi dan mendeskripsikan makna yang ada dalam naskah tersebut.

\section{HASIL DAN PEMBAHASAN Sejarah Longser}

Drama tradisional yang kini hampir punah di Jawa Barat, khususnya di daerah Bandung biasa disebut longser. Berdasarkan perkembangannya ada satu kelompok yang masih eksis. Hal tersebut dikarenakan pemimpin kelompok ini masih hidup sehingga masih terjadi kaderisasi. Menurut Ateng Jafar hal yang mempengaruhi perkembangan longser adalah pengikut dan simpati masyarakat terhadap pertunjukan longser itu sendiri. Kesenian longser mendapat pengaruh dari kesenian doger dan ketuk tilu yang merupakan jenis seni tari pergaulan yang berkembang di Bandung sebelum adanya longser.

Menurut Durachman (2009:24) secara tidak langsung kita harus mengetahui awal lahirnya longser baik berkaitan dengan arti atau sejarahnya longser itu sendiri. Oleh sebab itu, dalam kebudayaan Sunda terkenal dengan istilah kirata yang artinya dikira-kira tapi nyata. Longser mempunyai dua suku kata, yaitu long yang asalnya dari kata 'melong' dan ser yang artinya 'perasaan tertarik terhadap lawan jenis'. Jadi, bedasarkan prinsip kirata itu sendiri longser artinya perasaan tertarik hatinya oleh lawan jenis karena melong. Hal tersebut sama dengan pendapat Ateng Jafar yang menyebutkan bahwa ketika pertunjukan longser banyak penonton yang tertarik oleh pemain longser itu sendiri. 


\section{Analisis Struktural Naskah "Mad Toing" Ringkasan Cerita "Mad Toing"}

Naskah longserinimenceritakan sekelompok orang yang sedang mengamen di daerah kebun yang jauh dari hiruk pikuk masyarakat. Perlengkapan yang mereka gunakan berupa waditra yang terdiri dari kendang, kempul, dan goong. Mereka beranggapan walaupun mereka ngamen di tempat tersebut pasti banyak warga yang melihat pertunjukan mereka. Hal tersebut dikarenakan adanya perubahan dari jaman ke jaman yang disebut mutakhir.

Cerita yang dibawakan oleh sekelompok orang itu adalah tentang gambaran tokoh yang bernama "Mad Tohir" yang badannya begéng, bujur tépos, beuteung nyemplu, cacingeun, panonna beureum jéér, tukang ngadu, ngomongna balabab-belebeb rada sarap jeung leumpangna siga Si Ajow.

Awalnya Mad Tohir sebagai tokoh ciptaan saja, tapi lama-lama ada mengaku menjadi sosok tersebut. Dengan segala kelicikannya dan tipu daya dia meyakinkan orang-orang bahwa dia itu Mad Tohir yang sedang diceritakan oleh sekelompok orang pengamen itu. Mad Tohir memanfaatkan kesempatan tersebut untuk mencari keuntungan. Yang mengaku sebagai Mad Tohir itu nama aslinya adalah Mad Toing, suami dari Bu Enden. Singkat cerita datanglah $\mathrm{Bu}$ Enden yang membongkar kebohongan Mad Toing.

\section{Tema Naskah "Mad Toing"}

Setelah diidentifikasi, tema yang terdapat dalam naskah drama "Mad Toing" adalah tema kemanusiaan yang lebih memusatkan pada persoalan moral.

\section{Alur Cerita Naskah "Mad Toing"}

Alur yang ada dalam cerita ini adalah alur maju (progresif). Kejadian-kejadian yang dibahas secara kronologis dari awal, tengah, sampai ahir cerita.

\section{Urutan kajadiannya adalah:}

\section{1. Éksposisi}

Naskah ini dimulai dengan memperkenalkan pelaku beserta kegiatan yang dilakukannya. Kemudian disusul dengan menceritakan lokasi dan objek tujuanna.

\section{Konflikasi}

Konflik awal dalam naskah ini adalah ketika menentukan hiburan apa yang akan disajikan untuk penonton.

\section{Klimaks}

Yang menjadi klimaks dalam naskah ini adalah ketika ada orang yang mengakungaku bernama Mad Tohir, sama seperti yang diceritakan oleh sekelompok orang pengamen itu.

\section{Antiklimaks}

Bagian dari kejadian yang memperlihatkan antiklimaks adalah ketika Lelaki I meminta maaf kepada Mad Toing, tetapi Mad Toing memberikan syarat berupa uang untuk membeli maafnya.

\section{Resolusi}

Gambaran carita yang menunjukan resolusi yaitu ketika $\mathrm{Bu}$ Enden istrinya Mad Toing datang dan memberitahu kebenaran siapa itu Mad Toing.

\section{Tokoh dalam Naskah "Mad Toing”}

Tokoh yang berperan dalam cerita ini adalah (1) Lelaki I, (2) Lelaki II, (3) Lelaki III, (4) Lelaki IV, (5) Wanita, (6) Penonton I, (7) Penonton II, (8) Penonton III, (9) Penonton IV, (10) Mad Toing, dan (11) Bu Endén. Yang menjadi tokoh utamanya adalah Mad Toing.

\section{Latar dalam Naskah "Mad Toing”}

Dari naskah longser yang berjudul "Mad Toing" terdapat 10 latar yang terbagi dalam 3 kriteria, seperti di bawah ini:

a. Latar sosial ada $6(60 \%)$

b. Latar géografis ada $3(30 \%)$

c. Latar waktu ada $1(10 \%)$ 


\section{Sudut Pandangdalam Naskah "Mad Toing"}

Dalam naskah longsér "Mad Toing", pengarang menggunakan sudut pandang orang pertama, first person.

\section{Gaya Bahasa dalam Naskah "Mad Toing"}

Setelah dianalisis terdapat 10 gaya bahasa, diantaranya:

a) Gaya bahasa simile ada $2(20 \%)$

b) Gaya bahasa hiperbola ada $4(40 \%)$

c) Gaya bahasa ironi ada $3(30 \%)$

d) Gaya bahasa eponym ada $1(10 \%)$

Tabel 1

Analisis Unsur-Unsur Drama Naskah "Mad Toing"

\begin{tabular}{ccccc}
\hline No. & Jenis & Ada & Tidak & Keterangan \\
\hline 1. & Prolog & $\sqrt{ }$ & & \\
\hline 2. & Dialog & $\sqrt{ }$ & & 137 dialog \\
\hline 3. & Babak & & $\sqrt{ }$ & 10 adegan \\
\hline 4. & Adegan & $\sqrt{ }$ & & \\
\hline 5. & Wawancang & $\sqrt{ }$ & & \\
\hline 6. & Solilokui & & $\sqrt{ }$ & \\
\hline 7. & Aside & & $\sqrt{ }$ & \\
\hline 8. & Epilog & & $\sqrt{ }$ & \\
\hline
\end{tabular}

\section{Unsur Semiotik dalam Naskah Longser "Mad Toing"}

Semiotik berasal dari bahasa Yunani, yaitu semeion yang artinya tanda. Semiotok biasa diartikan sebagai ilmu tanda. Tanda ada di mana-mana; kata adalah tanda, begitu juga gerak isyarat. Struktur film, struktur karya sastra, bentuk bangunan atau suara burung dianggal sebagai tanda. Menurut Luxemburg (1992:44), semiotik adalah ilmu yang secara sitematis meneliti tentang tanda-tanda dan lambang-lambang, sistem-sistem beserta proses perlambangnya. Wellek (1986), memasukan image (citra), methapor (metefora), symbol (lambang), danmyth (mitos) ke dalam cakupan ilmu semiotik.

Semiotika adalah ilmu mengenai tandatanda, yang menganggap fenomena sosial masyarakat dan kebudayaan berupa tandatanda. Semiotik juga meneliti kemungkinan sistem-sistem, aturan-aturan, dan konversi tanda-tanda yang mempunyai arti (Pradopo, 2010:119).

Berdasarkan kajian di atas dapat disimpulkan bahwa semiotik adalah ilmu mengenai tandatanda yang terdapat dalam kehidupan. Tandatanda tersebut dapat berupa kata, isyarat, simbol, struktur karya sastra, struktur film, termasuk fenomena sosial dan kebudayaan yang terdapat di masyarakat. Tanda-tanda mempuyai makna secara optimal yang digunakan dalam tindak komunikasi, dan seterusnya diteliti menggunakan ilmu semiotik.

Unsur-unsur sémiotik menurut Pierce (Santosa, 1993:10), terbagi menjadi tiga, yaitu:

1) Hubungan petanda dengan warna tandanya, meliputi:

a. Qualisign: hubungannya dengan kualitas;

b. Sinsign: hubungannya dengan kanyataan; dan

c. Legisign: hubungannya dengan kaidah.

2) Hubungan kenyataan dengan warna dasarnya, meliputi:

a. Ikon: suatu hal yang melaksanakan fungsi sebagai penanda salah satu objek atau yang sejenis;

b. Indéks: suatu hal yang melaksanakan fungsi sebagai penanda yang menunjukan petanda; dan

c. Simbol: suatu hal yang melaksanakan fungsi sebagai penanda berdasarkan konvensi yang dipakai di masyrakat. 


\section{Tanda Ikon dalam Naskah "Mad Toing"}

Dalam naskah "Mad Toing" terdapat 7 tanda ikon yang terbagi ke dalam dua kritéria, di antaranya: ikon imagi ada $6(85,71 \%)$ dan ikon métapora ada 1 (14,28\%), sedangkang untuk ikon diagramatis tidak ditemukan.

\section{Tanda Indeks dalam Naskah "Mad Toing”}

Dalam naskah "Mad Toing” terdapat 20 indéks yang terbagi ke dalam 4 katégori, di antaranya: a) indéks kelakuan ada 12 (60\%); indéks gerak-gerik ada 3 (15\%); indéks gejala fisik ada $3(15 \%)$; dan indéks aktualisasi ada 2 (10\%).

\section{Simbol dalam Naskah "Mad Toing"}

Dalam naskah ini pun terdapat 11 simbol yang ditemukan.

\section{Analisis Struktural Naskah "Tisolédat" Ringkasan Cerita Naskah "Tisolédat"}

Isi dari naskah ini menceritakan sepasang pengantin baru yang bernama Aden dan Eneng. Mereka sedang jalan-jalan menikmati masamasa bulan madunya. Ketika mereka sedang berjalan, paranayaga memperingatkan mereka supaya tidak melewati saluran air yang jalannya licin. Para nayaga menyuruh mereka supaya melewati jembatan penyebrangan. Pasangan itu tidak mendengarkan nasihat nayaga itu, sampai akhirnya Aden terpeleset menginjak kulit pisang raja buluh, dia pingsan dan geger otak.

Bapa Baplang mertuanya Adén marah ketika mengetahui kalau menantunya terjatuh menginjak kulit pisang raja buluh. Mertuanya itu mencari-cari siapa yang membuang kulit pisang tersebut, dengan menuduh nayaga, tukang bajigur, tukang pisang goreng, Hasan Epen (yang mempunyai perkebunan pisang), dan Mang Toha, tapi tuduhannya itu tidak terbukti sama sekali. Ketika masih mencari siapa pelakunya, rombongan Bapa Baplang bertemu dengan Ibu Sepuh. Ibu sepuh adalah besannya Bapa Baplang. Ketika itu Ibu Sepuh sedang membawa sekantong kulit pisang. Setelah ditanya ternyata benar Ibu Sepuh yang membuang kulit pisang raja buluh ke saluran pembuangan air.

\section{Tema dalam Naskah "Tisolédat"}

Téma dalam naskah "Tisolédat" adalah kemanusiaan yang fokusnya menunjukan tingginya martabat manusia, contohnya nasehat orang tua.

\section{Alur Naskah dalam Naskah "Tisolédat"}

Alur yang digunakan dalam naskah ini adalah alur maju (progrésif).

Gambaran seritanya seperti di bawah ini.

1. Eksposisi

Cerita ini dimulai dari gambaran pengantin baru yang sedang berjalan-jalan.

2. Konflikasi

Konfikasi yang terjadi dari naskah "Tisolédat" ketika si pengantin baru yang sedang berjalan-jalan itu tetap melewati saluran pembuangan air yang licin, dan Aden terjatuh menginjak kulit pisang raja buluh.

3. Klimaks

Puncak cerita dalam naskah "Tisolédat" yaitu ketika Bapa Baplang mencari dan asal menuduh siapa yang membuang kulit pisang raja buluh.

4. Antiklimaks

Bagian dari cerita yang menggambarkan antiklimaks yaitu ketika Bapa Baplang, Tukang Bajigur, Hasan Epen, Tukang Pisang Goreng, dan Mang Toha bertemu Ibu Sepuh yang membawa kantong keresek yang isinya kulit pisang raja buluh.

5. Resolusi

Resolusinya ketika Ibu Sepuh mengakui bahwa dirinya yang membuang kulit pisang raja buluh ke saluran pembuangan air, sehingga menyebabkan anaknya Aden sampai geger otak.

\section{Tokoh dalam Naskah "Tisolédat"}

Tokoh dalam naskah "Tisolédat" adalah 1) Nayaga I, 2) Nayaga II, 3) Nayaga III, 4) Nayaga IV, 5) Adén, 6) Enéng, 7) Bu Endén, 8) Bapa Baplang, 9) Tukang bajigur, 10) Tukang pisang goréng, 11) Hasan Épén, 12) Mang Toha, dan 13) Ibu Sepuh. Tokoh utamanya adalah Bapa Baplang. 


\section{Latar dalam Naskah "Tisolédat"}

Latar yang ditemukan dalam naskah "Tisolédat" ini ada 30 latar dan terbagi ke dalam3 kelompok, yaitu: a) latar sosial 12 (40\%); b) latar géografis 17 (56,6\%); dan c) latar waktu $1(3,3 \%)$.

\section{Sudut Pandang dalam Naskah "Tisolédat"}

Sudut pandang yang terdapat dalam naskah "Tisolédat" yaitu pengarang menggunakan sudut pandang orang pertama.

\section{Gaya Bahasa dalam Naskah "Tisolédat"}

Setelah dianalisis ditemukan adanya 20 gaya bahasa dalam naskah "Tisolédat", yaitu: a) alegori $3(15 \%)$; b) hiperbola 5 (25\%); c) ironi 2 (10\%); d) litotes $2(10 \%)$; e) simile 3 (15\%); f) épitét ada 4 (20\%); dan g) personifikasi $1(5 \%)$

Tabel 2

Analisis Unsur-Unsur Drama Naskah "Tisolédat"

\begin{tabular}{ccccc}
\hline No. & Jenis & Ada & Tidak & Keterangan \\
\hline 1. & Prolog & $\sqrt{ }$ & & \\
\hline 2. & Dialog & $\sqrt{ }$ & & 207 dialog \\
\hline 3. & Babak & & $\sqrt{ }$ & 4 adegan \\
\hline 4. & Adegan & $\sqrt{ }$ & & 38 wawacang \\
\hline 5. & Wawancang & $\sqrt{ }$ & $\sqrt{ }$ & \\
\hline 6. & Solilokui & & & \\
\hline 7. & Aside & $\sqrt{ }$ & & \\
\hline 8. & Epilog & $\sqrt{ }$ & & \\
\hline
\end{tabular}

Unsur Semiotik dalam Naskah Longsér"“Tisolédat Tanda Ikon dalam naskah "Tisolédat"

Dalam naskah "Tisolédat" terdapat 10 (100\%) ikon imagi. Dalam naskah ini tidak terdapat ikon diagramatis dan ikon métafora.

\section{Tanda Indéks dalam Naskah "Tisolédat"}

Indeks yang terdapat dalam naskah “Tisolédat" ada 30 Indéks, terbagi ke dalam 4 kategori, diantaranya:

a) Indéks Kelakuan ada 17 (56,6\%)

b) Indéks Gejala alam ada $1(3,3 \%)$

c) Indéks Fisik ada $3(9,9 \%)$

d) Indéks Aktualisasi ada 9 (29.9\%)

\section{Tanda Simboldalam naskah "Tisolédat"}

Dalam naskah "Tisolédat" ditemukan 11 simbol.

\section{Bahan Ajar Pangajaran Drama di SMA/ MA/SMK}

Berdasarkan hasil analisis naskah longser "Mad Toing" dan "Tisolédat" maka dapat dijadikan alternatif dalam pembelajaran drama. Bahan pembelajaran harus berdasarkan tujuan yang akan dicapai. Bahan pembelajaran juga harus sesuai dengan perkembangan siswa SMA/ MA/SMK. Di bawah ini dijelaskan Rencana Pelaksanaan Pembelajaran (RPP) sebagai alternatif pembelajaran drama di SMA/MA/ SMK. 


\section{RENCANA PELAKSANAAN PEMBELAJARAN (RPP)}

I. Mata Pelajaran : Bahasa Sunda

Kelas : XI

Semester $: 2$

Jumlah Pertemuan : 3 kali pertemuan

Pertemuan ke- $\quad: 1$

\section{STANDAR KOMPETENSI}

11.2 Mampu berbicara untuk mengungkapkan pikiran, perasaan, dan keinginan dalam menyampaikan berita/ pengumuman/ pesan, bercerita, memimpin rapat, berwawancara, dan bermain peran.

\section{KOMPETENSI DASAR}

11.2.5 Bermain peran (ngaragakeun)

\section{INDIKATOR}

1. Dapat membaca dan memahami téks drama yang akan diperankan.

2. Dapat menghayati watak tokoh yang akan diperankan.

3. Dapat memperagakan tokoh dengan memperhatikan penggunaan lafal, mimik, gerak-gerik yang tepat sesuai dengan watak tokoh cerita.

4. Dapat memberikan komentar terhadap bahasa maupun ekspresi yang diungkapkan teman.

\section{TUJUAN PEMBELAJARAN}

1. Membaca dan memahami téks drama yang akan diperankan.

2. Menghayati watak tokoh yang akan diperankan.

3. Memperagakan tokoh dengan memperhatikan penggunaan lafal, mimik, gerak-gerik yang tepat sesuai dengan watak tokoh cerita.

4. Memberikan komentar terhadap bahasa maupun ekspresi yang diungkapkan teman.

\section{MATERI AJAR}

Naskah Longsér

Penjelasan longser

Longser mempunyai dua suku kata, yaitu long yang asalnya dari kata melong dan ser yang artinya perasaan tertatik terhadap lawan jenis.Jadi bedasarkan prinsip kirata itu sendiiri longser artinya perasaan tertarik hatinya oleh lawan jenis karena melong. Hal tersebut sama dengan pendapat Ateng jafar yang menyebutkan bahwa ketika pertunjukan longser banyak penonton yang tertarik oleh pemain longser itu sendiri.

Naskah Longsér karya H.R Hidayat Suryalaga "Mad Toing" atau "Tisolédat"

\section{ALOKASI WAKTU}

1 kali pertemuan ( 4 x 45 menit)

\section{METODE PEMBELAJARAN}

- Metode modeling

- Metode elektik

- Metode ceramah interaktif

\section{KEGIATAN PEMBELAJARAN}

Pertemuan 1 ( 2 x 45 menit)

\begin{tabular}{llll}
\hline No & \multicolumn{1}{c}{ Kegiatan Belajar } & $\begin{array}{c}\text { Waktu } \\
\text { (menit) }\end{array}$ & \multicolumn{1}{c}{$\begin{array}{c}\text { Aspek Life Skill yang } \\
\text { dikembangkan }\end{array}$} \\
\hline 1. & PENDAHULUAN & 15, & - Disiplin \\
& $-\quad$ Tegur sapa (mengabsen) & 15 \\
& $-\quad$ Mengadakan apersepsi dan memotivasi siswa untuk belajar lebih giat \\
& $-\quad$ Memberikan penjelasan tentang kateri yang akan dipelajari & & - Menyimak \\
\hline
\end{tabular}




\begin{tabular}{|c|c|c|c|}
\hline 2. & $\begin{array}{l}\text { KEGIATAN INTI: } \\
\text { Eksplorasi } \\
\text { - } \text { Guru memberikan penjelasan pengertian konsep drama tradisional } \\
\text { - Membaca dan memahami naskah longsér yang akan diperankan } \\
\text { - } \text { Kenghayati watak tokoh yang akan diperankan } \\
\text { - Guru memberikan kesempatan kepada siswa untuk menanyakan hal-hal } \\
\quad \text { yang dimengerti mengenai materi di atas }\end{array}$ & $65^{\prime}$ & $\begin{array}{l}\text { - Disiplin } \\
\text { - Menyimak } \\
\text { - Berbicara } \\
\text { - Mencatat }\end{array}$ \\
\hline 3. & $\begin{array}{l}\text { PENUTUP } \\
\text { - } \quad \text { Menyimpulkan dan menegaskan materi yang dipelajari } \\
\text { - } \quad \text { Evaluasi/tanya jawab } \\
\text { - } \quad \text { Memberi tugas terstruktur }\end{array}$ & $10^{\prime}$ & \\
\hline
\end{tabular}

\section{Pertemuan 2 (2 x 45 menit)}

\begin{tabular}{|c|c|c|c|}
\hline No & Kegiatan Belajar & $\begin{array}{l}\mathrm{W} \text { a } \mathrm{k} \mathrm{t} \mathrm{u} \\
\text { (menit) }\end{array}$ & $\begin{array}{l}\text { Aspek Life Skill yang } \\
\text { dikembangkan }\end{array}$ \\
\hline 1. & $\begin{array}{l}\text { PENDAHULUAN } \\
-\quad \text { Tegur sapa (mengabsen) } \\
-\quad \text { Menjelaskan tujuan pembelajaran }\end{array}$ & $10^{\prime}$ & $\begin{array}{l}\text { - Disiplin } \\
\text { - Menyimak }\end{array}$ \\
\hline 2. & $\begin{array}{l}\text { KEGIATAN INTI: } \\
\text { * } \text { Eksplorasi } \\
\text { - } \text { Guru memberikan penjelasan téknis ngaragakeun longsér } \\
\text { Memperagakan tokoh dengan memperhatikan penggunaan lafal, mimik, } \\
\text { gerak-gerik yang tepat sesuai dengan watak tokoh cerita } \\
\text { Memberikan komentar terhadap bahasa maupun ekspresi yang } \\
\text { diungkapkan teman } \\
\text { - Konfirmasi } \\
\text { Guru memberikan kesempatan kepada siswa untuk menanyakan hal-hal } \\
\text { yang dimengerti mengenai materi di atas }\end{array}$ & $75^{\prime}$ & $\begin{array}{l}\text { - Disiplin } \\
\text { - Menyimak } \\
\text { - Berbicara } \\
\text { - Praktek }\end{array}$ \\
\hline 3. & $\begin{array}{l}\text { PENUTUP } \\
\text { - Evaluasi kegiatan belajar mengajar dilakukan pada saat proses belajar } \\
\text { mengajar bermodeling dengan format penilaian yang telah disediakan }\end{array}$ & 5 , & \\
\hline
\end{tabular}

\section{PENILAIAN HASIL BELAJAR}

1. Instrumen Evaluasi (butir soal)

1) Apa tema yang terdapat dalam naskah longser?

2) Sebutkan dan jelaskan unsur-unsur intrinsik yang terdapat dalam naskah longsér?

3) Apa makna yang terdapat dalam naskah longser yang sedang anda perankan?

\section{Pedoman Penilaian}

\section{Format Penilaian Pemerana Drama}

\begin{tabular}{cll}
\hline No. & \multicolumn{1}{c}{ Aspek yang dinilai } & Kritéria \\
\hline 1. & Ucapan & Jelas \\
\hline 2. & Intonasi & Sesuai \\
\hline 3. & Mimik muka & Sesuai/tidak \\
\hline 4. & Pemakaian bahasa & Benar/baku \\
\hline 5. & Diksi & Sesuai \\
\hline 6. & Penampilan & Wajar/sopan \\
\hline 7. & Perhatian Ke Audience & Wajar \\
\hline Jumlah Skor & & \\
\hline
\end{tabular}




\section{Soal Tugas Terstruktur}

1) Baca dan perankan Naskah Longser tersebut!

2) Barikan komentar tentang basa dan ekspresi terhadap pemeranan!

\section{Soal Tugas Mandiri Tidak Terstruktur}

Coba pelajari lagi naskah longser yang kalian baca!

\section{MEDIA DAN SUMBER PEMBELAJARAN}

1. Buku Santika Basa, penerbit CV. King Qlaban Bandung

2. Naskah longsér karya H. R Hidayat Suryalaga

3. Kamus Basa Sunda R. A. Danadibrata

\section{SIMPULAN}

Masalah yang yang diteliti dalam penelitian struktur-semiotik naskah longser "Mad Toing", dan "Tisolédat" adalah struktur drama yang meliputi, tema, fakta cerita (tokoh, setting, alur), sarana cerita (sudut pandang, gaya bahasa), unsur drama (prolog, dialog, pembabakan, adegan, wawacang, silolokui, aside, dan epilog). Selain itu, diteliti pula makna (ikon, indeks, simbol) yang terdapat dalam naskah tersebut.

Hasil analisis dari naskah "Mad Toing" yaitu, tema; kemanusiaan, alur; maju, terdapat 11 pelaku, 1 pelaku utama dan 10 pelaku tambahan, terdiri dari 10 latar yang termasuk kategori latar sosial ada $6(60 \%)$, latar geografis ada $3(30 \%)$, dan latar waktu ada 1 (10\%), dalam naskah ini pengarang menggunakan sudut pandang orang ke satu "first person", gaya bahasa; 10 yang terbagi ke dalam gaya bahasa simile ada $2(20 \%)$, gaya bahasa hiperbola ada $4(40 \%)$, gaya bahasa ironi ada $3(30 \%)$, dan gaya bahasa eponym ada $1(10 \%)$

Unsur-unsur drama dalam naskah "Mad Toing" adalah prolog yang menggambarkan tokoh, tempat kejadian, dan gambaran awal berlangsungnya cerita, dialog dalam naskah ini terdapat 137 dialog, termasuk drama satu babak, adegan; 10, wawancang; 24, tidak ditemukan adanya solilokui, aside dan epilog.
Unsur-unsur semiotik yang terdapat dalam naskah "Mad Toing" ikon; 7 yang terbagi ke dalam 3 kriteria, diantaranya: ikon imagi ada $8(85,71 \%)$, ikon diagramatis; 0 , dan ikon metafora ada $1(14,28 \%)$; indeks ada 20 yang terbagi ke dalam 4 kategori, yaitu: indeks kelakuan ada 12 (60\%), indeks gerak-gerik ada $3(15 \%)$, indeks gejala fisik ada $3(15 \%)$, indeks aktualisai ada $2(10 \%)$, dan ikon ada 11 jenis.

Hasil analisis yang terdapat dalam naskah "Tisolédat" adalah, tema; kemanusiaan, alur; maju, tokoh; 13 yang terbagi 1 orang tokoh utama dan 12 tokoh tambahan, latar; 30 yang terbagi ke dalam 3 kategori, yaitu; latar sosial $12(40 \%)$, latar geografis ada $17(56,6 \%)$, latar waktu ada $1(3,3 \%)$, sudut pandang; orang pertama, gaya bahasa; 20 yang terdiri dari gaya bahasa alegori ada $3(15 \%)$, gaya bahasa hiperbola ada 5 (25\%), gaya bahasa ironi ada 2 $(10 \%)$, gaya bahasa litotes ada $2(10 \%)$, gaya bahasa simole ada $3(15 \%)$, gaya bahasa epitet ada $4(20 \%)$, dan gaya bahasa personifikasi ada $1(5 \%)$

Unsur-unsur drama dalam naskah "Tisolédat" adalah, adanya prolog yang menggambarkan pelaku beserta kebiasaannya, dialog; 207, termasuk drama satu babak, adegan; 2, wawancang; 38, tidak ditemukan adanya solilokui, aside;1, ditemukan juga adanya epilog.

Unsur-usnur semiotik yang terdapat dalam naskah "Tisolédat", ikon; 10 yang terbagi ke dalam 3 kriteris, yaitu ikon imagi ada 10 (100\%), ikon diagramatis ada 0 , dan ikon metafora 0 , indeks; 30 yang terbagi menjadi 4 kriteria, diantaranya indeks kalakuan ada $17(56,6 \%)$, indeks gejala alam ada $1(3,3 \%)$, indeks fisik ada $3(9,9 \%)$, indeks aktualisasi ada $9(29,9 \%)$, dan simbol ada 11 jenis.

\section{PUSTAKA RUJUKAN}

Durachman, Yoyo C. 2009. Teater Tradisional \& Teater Baru. Bandung: STSI Press.

Koswara, Dedi. 2011. Racikan Sastra: Pangdeudeul Bahan Perkuliahan Sastra Sunda (Diktat). Bandung. JPBD FPBS UPI. 
Luxemberg, J. V, dkk. 1992. Pengantar Ilmu Sastra (Terjemahan Dick Hartoko). Jakarta: Gramedia.

Pradopo, Rahmat Joko. 2010. Beberapa Teori Sastra, Metode Kritik dan Penerapannya. Yogyakarta: Pustaka Pelajar Offset.

Santosa, Puji. 1993. Ancangan Semiotik dan Pengkajian Sastra. Bandung: Angkasa.

Wellek, Rene dan Austin Warren. 1986. Theory of Literature "Teori Kesustraan" (terjemahan dalam Bahasa Indonesia oleh Melani Budianta). Jakarta: Sumber Agung.

\section{UCAPAN TERIMA KASIH}

Penulis mengucapkan terima kasih dan penghargaan yang sebesar-besarnya kepada Prof. Dr. Iskandarwassid, M.Pd. dan Dr. Dedi Koswara, M.Hum. sebagai pembimbing. Selain itu, juga kepada Ketua Prodi Pendidikan Bahasa dan Budaya Sunda SPs UPI dan Ketua Prodi Jurusan Pendidikan Bahasa Daerah FPBS UPI. Terima kasih pula penulis sampaikan kepada redaksi Jurnal Lokabasa atas dimuatnya tulisan ini. 